\title{
Ervaringen met de introductie van het individueel opleidingsprogramma bij huisartsen in opleiding aan het VUmc
}

\author{
G. Locher, W.H. Koerten
}

\section{Samenvatting}

Inleiding en vraagstelling: Als voorproef op de invoering van het vernieuwde curriculum, hebben huisartsen in opleiding (haio's) aan de Huisartsopleiding van het VUmc (HOVUmc) de opdracht gekregen een individueel opleidingsprogramma (IOP) te maken. Onderzocht is wat voor IOP de haio's hebben gemaakt, hoe zij het gebruikt hebben, hoe de leeromgeving met het IOP omging en als hoe nuttig de haio's het IOP hebben ervaren.

Methoden: De onderzoeksvragen zijn vertaald in een schriftelijke enquête en voorgelegd aan de haio-groepen, die in maart 2003 aan de HOVUmc zijn gestart met het eerste of derde opleidingsjaar. In beide jaren lopen zij stage in de huisartspraktijk.

Resultaten: 68 van de 72 mogelijke respondenten (90\%) hebben de vragenlijst ingevuld. Meer dan de helft van de respondenten werkte met slechts een lijstje van leerpunten. Men gebruikte het IOP in meerderheid voor het plannen van leeractiviteiten; een minderheid gebruikte het ook voor het achteraf verantwoorden van het leren. Meest genoemde punten waarvoor het IOP nuttig werd gevonden: vat krijgen op lacunes en het plannen van leergesprekken met de opleider. Hoe intensiever de opleiders werkten met het IOP, hoe nuttiger de haio's het IOP vonden.

Conclusie en discussie: Het IOP wordt beter gebruikt en er wordt gemotiveerder aan gewerkt als het niet wordt behandeld als individuele opdracht, maar meer als leercontract, waarvoor de opleider op de stageplaats en de haio even verantwoordelijk zijn. De rol van de opleiding kan dan zijn: het begeleiden van het koppel haio-huisartsopleider bij het maken en uitvoeren van het IOP. (Locher G, Koerten WH. Ervaringen met de introductie van het individueel opleidingsprogramma bij huisartsen in opleiding aan het VUmc. Tijdschrift voor Medisch Onderwijs 2005;24(2):78-86.)

\section{Inleiding en vraagstelling}

De huisartsopleiding is een driejarige opleiding, waarin de studenten (huisartsen in opleiding, kortweg haio's) voornamelijk stage lopen. Eén dag per week brengen zij door op de opleiding en krijgen daar onderwijs (het 'terugkomdagonderwijs' genoemd). In het eerste zowel als het derde opleidingsjaar lopen zij stage in de huisartspraktijk en worden zij begeleid in een één op één leersituatie door een daartoe erkende huisartsopleider. In het tweede opleidingsjaar lopen zij stages buiten de huisartspraktijk (als poortarts, in de Geestelijke Gezondheidszorg en/of in een verpleeghuis).
In de huisartsopleiding wordt momenteel landelijk gewerkt aan een structurele vernieuwing van het curriculum, die de haio een grotere verantwoordelijkheid geeft voor diens eigen leren. ${ }^{1}$ Achtergrond van die vernieuwing in de opleiding vormt het constructivisme, een richting in de leerpsychologie, waarin men ervan uitgaat dat de student het meest effectief leert als het leren actief gebeurt en hij er zelf verantwoordelijk voor is..$^{2-4}$

In de constructivistische opvatting heeft het portfolio een belangrijke plaats. Een portfolio bevat een aantal kenmerken: (1) het is een verzameling van het werk van 
de student, (2) het is door de student zelf samengesteld, (3) het geeft een goed gedocumenteerd beeld van de groei en ontwikkeling in competenties, (4) het bevat reflectie, vastgelegd in documenten waarin keuzes worden toegelicht, en (5) de samenstelling is begeleid door een docent of coach. In de literatuur wordt een onderscheid gemaakt tussen een presentatieportfolio en een ontwikkelingsportfolio. Het presentatieportfolio is vooral bedoeld voor selectieve beoordelingen, terwijl het ontwikkelingsportfolio een functie heeft voor formatieve toetsing. Binnen dit portfolio wordt o.a. een analyse van sterke en zwakke punten opgenomen en een persoonlijk ontwikkelingsplan (POP), waarin studenten de planning voor verdere ontwikkeling schetsen. ${ }^{5-6}$

Binnen de huisartsopleiding wordt het POP het IOP genoemd: het individueel opleidingsprogramma, omschreven als "een door de haio zelf geformuleerd plan voor een voorliggende periode, waarin hij zijn eigen leerdoelen, leeractiviteiten en toetsen beschrijft". Hoe een goed en volledig IOP er uit moet zien, is binnen de opleiding doordacht. Belangrijk criterium daarbij is concreetheid en haalbaarheid. Dat heeft geleid tot een structuur voor het IOP met de volgende punten:

1. Een lijst van relevante leerdoelen.

2. Een uitspraak over wat de haio zou willen leren met betrekking tot dat specifieke leerdoel.

3. Een uitspraak over de lacune die de haio ervaart met betrekking tot dat leerdoel.

4. Een plan van aanpak.

5. Een concreet omschreven leerresultaat, eventueel voorzien van een methode van toetsing.

6. Een tijdspad.

De relevantie van de leerdoelen werd getoetst aan de omschrijving van de functies van de huisarts in het CCBOH-rapport. ${ }^{7}$ Dit resulteerde in competenties op het gebied van:

1. hulpverlening;

2. geneeskundige diagnostiek en behandeling;

3. ondersteunende taken;

4. persoonlijk functioneren;

5. leren.

Bovenstaande punten werden verwerkt in een schema dat reeds in het nog niet vernieuwde curriculum is voorgelegd aan de haio's om ervaring op te doen met dit instrument. De haio's hebben het schema ingevuld en actief gebruikt als leerplan. De verwachting was dat zij met het IOP gerichter zouden werken aan het opvullen van hun lacunes en het ontwikkelen van hun sterke punten, dat zij bewuster zouden kiezen voor bepaalde leermethodes, door hen te behandelen patiënten meer zouden afstemmen op hun leerdoelen, hun leer- en vrije tijd beter zouden structureren en gemakkelijker achteraf konden verantwoorden wat ze geleerd hadden.

In de literatuur worden enkele aandachtspunten genoemd bij de invoering van portfolio's: studenten moeten herkenbare afnemers hebben, er moet een duidelijke eigen inbreng van de student mogelijk zijn, en het moet de student duidelijk zijn waarvoor het portfolio dient. ${ }^{6}$

Mondelinge evaluaties gaven een indruk van de ervaringen met het IOP dat voor het eerst in 2001 werd geïntroduceerd. De reacties waren divers. Er waren haio's die het prettig vonden om ermee te werken, maar een groter aantal van hen leek het slechts te zien als een taakverzwaring: een opdracht die je voor de opleiding deed, maar waar je zelf niets aan had. Daarnaast was de diversiteit in 'leerplannen' groot: sommige haio's hadden geen leerplan of een heel summier puntenlijstje gemaakt. Anderen daarentegen hadden het IOP-schema van de oplei- 
ding geheel ingevuld. Haio's ervoeren de opdracht om een IOP te maken en de bespreking ervan ook wel als een tegenstrijdige boodschap. Enerzijds wordt benadrukt dat het IOP de haio eigen verantwoordelijkheid voor het leren geeft. Anderzijds moet een IOP voldoen aan door de opleiding gestelde eisen. Dat klinkt als: "Kies zelf, maar kies wel wat wij willen." Even divers waren de reacties van de groepsbegeleiders en de huisartsopleiders op het IOP. Sommigen probeerden elke door de haio gerapporteerde leerervaring onder te brengen in diens leerplan, anderen besteedden er helemaal geen aandacht aan.

Bovenstaande berichten over de eerste ervaringen voedden de behoefte om getalsmatige gegevens te verwerven over het IOP en wel met de volgende vragen:

1. Wat zijn de kenmerken van de IOP's die de haio's hebben gemaakt?

2. Hebben de haio's van het IOP het nut gehad zoals verwacht (voor het bijwerken van lacunes, het ontwikkelen van sterke punten, het kiezen van leermethodes, het structureren van leer- en andere activiteiten en het verantwoorden van wat is geleerd)?

3. Vonden de haio's het werken met een IOP nuttig en de moeite waard?

4. Wat is er tijdens het terugkomdagonderwijs met de IOP's gedaan?

5. Wat hebben de groepsbegeleiders gedaan met IOP's?

6. Wat hebben de huisartsopleiders gedaan met de IOP's van de haio's in de leergesprekken?

7. Is het zo dat de concreetheid van een IOP samenhangt met de mate waarin de groepsbegeleiders aandacht besteden aan het IOP? En: hangt de concreetheid van een IOP samen met de intensiteit, waarmee de huisartsopleiders het IOP gebruiken in de leergesprekken met hun haio's? Hangt het gebruik van en de te- vredenheid van de haio's met het IOP (vragen 2 en 3) samen met de intensiteit waarmee de huisartsopleiders het IOP gebruiken in de leergesprekken?

\section{Methoden}

\section{Procedure en onderzoeksgroep}

Eind september 2003 is een schriftelijke vragenlijst voorgelegd aan de haio's die in maart van dat zelfde jaar met het eerste of derde opleidingsjaar gestart waren en dus hun stage in de huisartspraktijk liepen. De enquête is afgenomen op het moment waarop de haio's aanwezig waren op het terugkomdagonderwijs en werd ter plekke op het instituut ingevuld. Op het tijdstip van enquêteren hebben haio's, de opleiders en de groepsbegeleiders minstens drie maanden de kans gehad om met een IOP te werken. Haio's uit het eerste en het derde jaar verschillen in de mate waarin zij gewend zijn met een IOP te werken: de derdejaars hebben ervaring met het IOP, de eerstejaars niet.

\section{Instrument}

Voor de eerste zes onderzoeksvragen is een vragenlijst geconstrueerd waarin de onderzoeksvragen als volgt zijn geoperationaliseerd.

Onderzoeksvraag 1: Welke kenmerken hadden de IOP's die de haio's hebben gemaakt?

De voorgelegde vraag bevatte de volgende, elkaar uitsluitende, naar concreetheid en uitgebreidheid oplopende alternatieven:

a. Geen IOP.

b. Een leerpuntenlijstje achteraf, waarin samengevat is op welke punten de haio wat heeft geleerd.

c. Een kort leerpuntenlijstje voor een komende periode.

d. Een leerpuntenlijstje met data (dag, maand). 
e. Een leerpuntenlijstje met data en nog meer (bijv. beschreven leeractiviteiten).

f. Een volledig ingevulde lijst volgens de door de HOVUmc ontworpen richtlijnen.

De haio werd gevraagd één van de alternatieven aan te kruisen.

Onderzoeksvraag 2: Hebben de haio's hun IOP gebruikt zoals bedoeld?

De haio's konden op een schaal van 1 (geheel mee oneens) tot 5 (geheel mee eens) reageren op de volgende stellingen:

a. "Doordat ik met mijn IOP werkte (-) kreeg ik meer vat op hoe ik mijn lacunes moest aanpakken, (-) kon ik meer aandacht besteden aan het ontwikkelen van mijn sterke punten, (-) kon ik de leergesprekken met mijn opleider beter benutten, (-) heb ik interessante stages gedaan (bijv. fysiotherapie, dermatologie), (-) was er een zinvolle afwisseling tussen studie en praktijk, (-) kon ik voor mijzelf meer nuttige patiënten zien."

b. "Mijn IOP heb ik gebruikt (-) om leergesprekken en leeractiviteiten te plannen, (-) achteraf goed te kunnen verantwoorden wat ik heb geleerd." Haio's, die aangaven niet met een IOP te hebben gewerkt, konden deze vraag overslaan of 'n.v.t.' aankruisen.

\section{Onderzoeksvraag 3: Vonden de haio's het} maken en gebruiken van een IOP de moeite waard?

Twee stellingen werden aan de haio's voorgelegd, waarop zij met behulp van een vijfpunts schaal (zie vraag 2 ) konden antwoorden:

a. "Mijn leerplan ervaar ik in het algemeen als ondersteunend voor mijn opleiding."

b. "In het algemeen vond ik het formuleren en bijstellen van een eigen leerplan een nuttige tijdsinvestering."
Onderzoeksvraag 4: Wat is er tijdens het terugkomdagonderwijs met het IOP gedaan? De vraag over dit onderwerp bevatte de volgende, naar intensiteit oplopende alternatieven:

a. Er wordt niet met mijn leerplan gewerkt.

b. Op de terugkomdag wordt er één keer per ongeveer zes weken naar gevraagd.

c. Op de terugkomdag worden leerervaringen die ik heb in verband gebracht met mijn leerplan.

d. Anders, nl...

Onderzoeksvraag 5: Hoe reageren de groepsbegeleiders op het IOP?

Op deze vraag konden de haio's de volgende antwoorden aangekruisen (meer dan één antwoord was mogelijk):

a. Naar inhoud: het IOP bevat alle categorieën van de eindtermen van de opleiding (hulpverlening, medisch handelen, ondersteunende taken, persoonlijk functioneren en leren).

b. Ook naar inhoud: het IOP bevat de onderwerpen waarvan de groepsbegeleiders vinden dat de haio ze moet leren.

c. Naar de methodiek van het leren.

d. Naar de methodiek van het toetsen.

e. Naar de concreetheid van de planning van leeractiviteiten.

f. Anders, nl...

Onderzoeksvraag 6: Hoe heeft de huisartsopleider met het IOP van de haio gewerkt? Bij de vraag over dit onderwerp werden antwoordalternatieven voorgelegd met een oplopende mate van intensiteit, waarvan de respondent er meer dan één kon aankruisen:

a. Mijn opleider vraagt er nooit naar.

b. Mijn opleider neemt eens in de 6-8 weken mijn leerplan met mij door (mijn initiatief, niet van de opleider).

c. Mijn opleider neemt eens in de 6-8 weken mijn leerplan met mij door (op initiatief van de opleider). 
d. Mijn opleider brengt punten in die hij mij wil leren en gaat na of ze in mijn leerplan vermeld zijn.

e. Bij vrijwel elk leergesprek brengt mijn opleider mijn leerervaringen in verband met mijn leerplan.

\section{Analyse}

De gegevens van de enquête zijn geanalyseerd met behulp van SPSS. De onderzoeksvraag naar de samenhang tussen enerzijds de concreetheid van het IOP en de mate waarin de haio's het programma gebruikten en het maken ervan zinvol vonden, en anderzijds de intensiteit waarmee tijdens het terugkomdagonderwijs en door de huisartsopleiders werd gewerkt met het IOP, werd beantwoord door een correlatie te berekenen tussen de beantwoording van de vragen 1, 2 en 3 enerzijds en 4, 5 en 6 anderzijds. Wanneer een respondent bij de vragen 5 en 6 meer dan één antwoord had aangekruist, dan werd het antwoord dat de grootste intensiteit weergaf, gebruikt als score. De correlatie werd berekend met een nonparametrische maat: de Spearman rangcorrelatiecoëfficiënt.

\section{Resultaten}

65 van de 72 haio's die deel uitmaakten van de groepen aan wie de enquête was voorgelegd, hebben de enquête ingevuld (90\%).

\section{Resultaten vraag 1}

Drieëndertig van de 65 respondenten (51\%) beperken zich tot een inhoudelijke lijst van punten. De rest (op één na) doet ook iets aan procedurebeschrijving: hoe ze leerdoelen gaan bereiken en wanneer. Tien van de 65 geven aan het complete HOVUmc-schema voor het IOP in te vullen $(15 \%)$.

\section{Resultaten vraag 2}

Tabel 1 laat zien dat haio's die het IOP gebruikten, er nut van hadden voor het opvullen van hun lacunes en de leergesprekken met hun opleiders. Slechts weinigen vonden het programma nuttig om met nieuwe onderwijsmethoden te leren werken, interessante stages te lopen, nuttige patiënten te zien of studie en praktijk zinvol af te wisselen.

\section{Resultaten vraag 3}

Meer respondenten waren het eens (40\%) dan oneens (27\%) met de stelling: "Mijn

Tabel 1a. Het door respondenten ervaren nut van het IOP.

\begin{tabular}{|c|c|c|c|c|c|c|c|c|}
\hline & & $\mathrm{N}$ & $\begin{array}{c}\text { Zeer } \\
\text { mee } \\
\text { oneens }\end{array}$ & Oneens & $\begin{array}{l}\text { Noch } \\
\text { eens/ } \\
\text { noch } \\
\text { oneens }\end{array}$ & Eens & $\begin{array}{l}\text { Zeer } \\
\text { mee } \\
\text { eens }\end{array}$ & Totaal \\
\hline \multicolumn{3}{|c|}{ Doordat ik met mijn IOP werkte ... } & $\%$ & $\%$ & $\%$ & $\%$ & $\%$ & $\%$ \\
\hline 1. & kreeg ik meer vat op mijn lacunes. & 61 & 7 & 21 & 29 & 38 & 5 & 100 \\
\hline 2. & $\begin{array}{l}\text { kon ik mijn sterke punten beter } \\
\text { ontwikkelen. }\end{array}$ & 59 & 8 & 42 & 27 & 20 & 2 & 100 \\
\hline 3. & $\begin{array}{l}\text { kon ik de leergesprekken met mijn } \\
\text { opleider beter benutten. }\end{array}$ & 60 & 5 & 25 & 27 & 32 & 12 & 100 \\
\hline 4. & heb ik interessante stages gedaan. & 55 & 24 & 16 & 25 & 29 & 5 & 100 \\
\hline 5. & $\begin{array}{l}\text { was er een zinvolle afwisseling tussen } \\
\text { studie en praktijk. }\end{array}$ & 58 & 14 & 33 & 33 & 19 & 2 & 100 \\
\hline 6. & kon ik nuttige patiënten zien. & 59 & 24 & 36 & 36 & 17 & 0 & 100 \\
\hline
\end{tabular}


Tabel 1b. Waar de respondenten hun IOP zoal voor gebruikten.

\begin{tabular}{|c|c|c|c|c|c|c|c|}
\hline & $\mathrm{N}$ & $\begin{array}{c}\text { Zeer } \\
\text { mee } \\
\text { oneens }\end{array}$ & Oneens & $\begin{array}{l}\text { Noch } \\
\text { eens/ } \\
\text { noch } \\
\text { oneens }\end{array}$ & Eens & $\begin{array}{l}\text { Zeer } \\
\text { mee } \\
\text { eens }\end{array}$ & Totaal \\
\hline Mijn IOP heb ik gebruikt om ... & & $\%$ & $\%$ & $\%$ & $\%$ & $\%$ & $\%$ \\
\hline $\begin{array}{l}\text { 1. mijn leergesprekken en -activiteiten } \\
\text { te plannen. }\end{array}$ & 61 & 3 & 14 & 17 & 55 & 6 & 100 \\
\hline $\begin{array}{l}\text { 2. achteraf goed te kunnen } \\
\text { verantwoorden wat ik heb geleerd. }\end{array}$ & 61 & 8 & 15 & 34 & 34 & 3 & 100 \\
\hline
\end{tabular}

IOP heb ik als ondersteunend voor mijn opleiding ervaren." De overige 33\% scoorde 'noch eens, noch oneens'. Met de stelling: "In het algemeen vond ik het maken van een IOP en het bijstellen ervan een nuttige tijdsinvestering" was 35\% het oneens tot geheel mee oneens, en $35 \%$ was het eens tot zeer eens. De overige 30\% scoorde 'noch eens, noch oneens'.

\section{Resultaten vraag 4}

De in tabel 2 aangegeven antwoordcategorieën 3-5 en 8, aangekruist door bij elkaar opgeteld 14\% van de respondenten, duiden er op dat er iets actiefs met het IOP is gedaan tijdens het terugkomdagonderwijs. Telt men de $19 \%$ van de respondenten, die melden dat eens in de zes weken naar het
IOP gevraagd wordt, er bij, dan betekent dit dat 33\% noemt dat het IOP tijdens het terugkomdagonderwijs na de introductie tenminste ter sprake is gekomen.

\section{Resultaten vraag 5}

In de verslaglegging beperken we ons tot de samenvattende categorieën:

1. Gericht op de inhoud van het IOP: leerdoelen en leerpunten, een samenvatting van de antwoordcategorieën a en b. 15\% van de respondenten kruiste alleen een van deze twee categorieën aan.

2. Gericht op het leerproces: het vaststellen van (kalender)data wanneer iets af moest zijn, methoden van leren en toetsen (een samenvatting van antwoordcategorieën c, d en e). $31 \%$ van

Tabel 2. Antwoorden op de vraag hoe tijdens de terugkomdag gewerkt werd met het IOP.

\begin{tabular}{llcc}
\hline & & $\mathrm{N}$ & $\%$ \\
\hline 1. & Wordt niet met mijn IOP gewerkt. & 40 & 62 \\
2. $\quad$ Eén keer per 6 weken wordt er naar gevraagd. & 12 & 19 \\
3. $\quad$ Leerervaringen worden in verband gebracht met IOP. & 5 & 8 \\
4. Anders 1: één keer per 6 weken wordt er naar gevraagd en leerervaringen & 2 & 3 \\
5. $\quad$ Anders 2: tijdens praktijkbezoek van groepsbegeleiders is over het IOP & 1 & 2 \\
6. $\quad$ Anders 3: IOP is niet gebruikt als basis voor leerpunten. & 1 & 2 \\
7. Oninterpretabele reactie bij "anders, nl...." & 2 & 3 \\
8. Anders 4: bij evaluatiegesprek met groepsbegeleiders. & 1 & 2 \\
\hline Totaal & 64 & 100 \\
\hline
\end{tabular}


de respondenten kruiste een of meer van deze categorieën aan.

3. Gericht op zowel de inhoud als het proces, dus een combinatie van categorieën die zowel onder 1 als 2 valt. 19\% beantwoordde zo de vraag.

4. N.v.t.: geen reactie van de groepsbegeleiders gehad (aangegeven door 34\%). Opvallend is dat het commentaar door de respondenten als meer procesgericht dan inhoudsgericht is ervaren.

\section{Resultaten vraag 6}

Tabel 3 geeft weer hoe de huisartsopleiders naar de ervaring van de haio's in de leergesprekken zijn omgegaan met het IOP. Antwoordcategorieën 1 en 2 in de tabel hebben gemeen dat de huisartsopleider passief blijft met betrekking tot het IOP. Dat wordt - bij elkaar opgeteld - door 38\% van de respondenten zo ervaren.

\section{Resultaten vraag 7}

Een statistisch significante correlatie werd aangetroffen tussen de concreetheid van een leerplan en het gebruik daarvan door de haio voor het plannen van leergesprekken en -activiteiten ( $r h o=0,33 ; \mathrm{p}<0,01$ ). Ook was er een verband tussen de mate waarin de respondenten het maken en bijstellen van een IOP nuttig vonden en de uitgebreidheid en concreetheid van het leerplan ( $r h o=0,29 ; \mathrm{p}<0,05)$. Op minder uitgebreide en concrete leerplannen werd door de groepsbegeleiders op meer aspecten gereageerd (rho=-0,28; $\mathrm{p}<0,05)$.

De intensiteit, waarmee de huisartsopleiders met het IOP werkten, toonde een statistischsignificantesamenhang methet gebruik dat de haio van diens IOP maakte om meer aandacht te besteden aan het ontwikkelen van diens sterke punten ( $r h o=0,35 ; \mathrm{p}<0,01)$, de leergesprekken met de huisartsopleider beter te benutten ( $r h o=0,34 ; \mathrm{p}<0,01)$ of een zinvolle afwisseling tussen studie en praktijk te krijgen ( $r h o=0,32 ; p<0,05)$. Ook bleek deze factor samen te hangen met de mate waarin de respondenten hun IOP als ondersteunend voor de opleiding ervoeren ( $r h o=0,34 ; \mathrm{p}<0,01$ ) en het nut dat de respondenten toeschreven aan het maken en bijstellen van een IOP ( $r h o=0,43 ; p<0,01)$. Voor het overige waren de gevonden correlatiecoefficiënten statistisch niet significant.

\section{Conclusie en discussie}

Samengevat per onderzoeksvraag zijn de resultaten als volgt:

Tabel 3. Mate van intensiteit waarmee opleiders werken met het IOP van haio's.

\begin{tabular}{|c|c|c|c|}
\hline & & $N$ & $\%$ \\
\hline \multicolumn{4}{|c|}{ Wat huisartsopleiders volgens respondenten doen met het IOP: } \\
\hline 1. & De opleider vraagt er nooit naar. & 13 & 22 \\
\hline 2. & $\begin{array}{l}\text { De opleider bespreekt het IOP eens in de 6-8 weken op initiatief van } \\
\text { de haio. }\end{array}$ & 9 & 15 \\
\hline 3. & $\begin{array}{l}\text { De opleider bespreekt het IOP eens in de } 6-8 \text { weken op eigen } \\
\text { initiatief. }\end{array}$ & 16 & 28 \\
\hline 4. & De opleider brengt leerpunten in en gaat na of ze in het IOP staan. & 11 & 19 \\
\hline 5. & $\begin{array}{l}\text { Bij vrijwel elk leergesprek brengt de opleider leerpunten in verband } \\
\text { met het IOP van de haio. }\end{array}$ & 9 & 15 \\
\hline \multicolumn{2}{|c|}{ Totaal } & 58 & 100 \\
\hline
\end{tabular}


1. $51 \%$ van de haio's maakt het IOP als een puntenlijstje, maar beschrijft geen methodes hoe die leerpunten te verwerven en geeft ook geen tijdsplanning. De overigen zijn iets uitgebreider.

2. Voor zover hun leerplannen dat ook toelaten, gebruiken haio's het IOP vooral voor het opvullen van hun lacunes en het plannen van leergesprekken met hun huisartsopleiders.

3. $40 \%$ ervoer het maken van een IOP als ondersteunend voor de opleiding, maar slechts 33\% vond het maken van een IOP een nuttige tijdsinvestering.

4. $33 \%$ geeft aan dat het IOP tijdens het terugkomdagonderwijs ter sprake is gekomen, 14\% (iets minder dan de helft van hen) gaf aan dat er iets actiefs mee gebeurde.

5. Groepsbegeleiders reageerden volgens de haio's vooral op wat het meest ontbrak in de IOP's: het hoe en wanneer bepaalde leerpunten gerealiseerd zouden worden.

6. $62 \%$ van de huisartsopleiders deed actief iets met het IOP van de haio's.

7. Naarmate de opleiders er intensiever mee bezig waren, gebruikten de haio's hun IOP meer voor het ontwikkelen van hun sterke punten, het plannen van hun leergesprekken en het verkrijgen van een zinvolle afwisseling tussen studie en praktijk. Tevens ervoeren de haio's het maken van een leerplan meer als ondersteunend en bleken zij het maken van een IOP zinvoller te vinden. Dit bevestigt wat in de inleiding reeds is vermeld uit de literatuur: als de opleider vraagt naar het IOP van de haio en er wat mee doet, dan zal het enthousiasme van de haio om een IOP te maken en bij te stellen groter zijn en zal hij of zij het meer benutten.

Om een enthousiastere ontvangst bij de haio's, een betere uitwerking van het IOP (met name de procesuitwerking) en een intensiever gebruik van het IOP te bewerkstelligen, stellen we de volgende maatregelen voor:

1. Behandel het IOP als een leercontract, voor het opstellen en afwerken waarvan de huisartsopleider en de haio samen verantwoordelijk zijn. De rol van de docenten die de haio-groepen tijdens het terugkomdagonderwijs begeleiden is dan vooral beperkt tot het ondersteunen van het koppel huisartsopleiderhaio bij het opstellen en uitvoeren van het IOP. Deze maatregel beoogt ook het idee bij de haio's weg te nemen dat ze individueel verantwoordelijk zijn voor hun 'eigen leerproces', dat ze via de commentaren van de begeleiders toch min of meer opgelegd krijgen.

2. Het IOP dient duidelijker dan tot nu toe het geval is geweest, geplaatst te worden in het kader van het samenstellen van een portfolio. Het oogt logischer en makkelijker om aan de hand van een assessment plus een reflectie daarover (noodzakelijke onderdelen in een portfolio ${ }^{5}$ ) een ontwikkelingsprogramma te maken dan los daarvan.

Deze enquête heeft een aantal beperkingen. Het beeld dat naar voren komt, wordt objectiever door bijvoorbeeld ook gegevens te verzamelen onder de opleiders (hetgeen bij de groepen die het nieuwe curriculum op de HOVUmc volgen ook gebeurt) en de IOP's zelf naar kenmerken te scoren in plaats van de beschrijving van de haio's te gebruiken als data.

De als schaal gebruikte antwoordcategorieën voor het vaststellen van de intensiteit van de reactie op het IOP tijdens het terugkomdagonderwijs (onderzoeksvraag 4) en de intensiteit waarmee er met een IOP wordt gewerkt door huisartsopleiders (onderzoeksvraag 6) zijn gebaseerd op wat we in de praktijk hebben waargenomen 
en in de interviews hebben gehoord. Een status als meetinstrument hebben ze niet: hun eigenschappen zijn niet onderzocht.

Een vervolgevaluatie kan gericht worden op het effect van het IOP als onderwijscontract tussen haio en huisartsopleider op de kenmerken van het door de haio's gemaakte IOP, het gebruik ervan door haio's en opleiders, en het door zowel de haio's als huisartsopleiders ervaren nut. Daarvoor moet dan een waarnemingsinstrument geconstrueerd worden om zowel bij de haio als de huisartsopleider de mate vast te leggen waarin een IOP gebruikt wordt als contract. Dit levert dan tevens een nadere concretisering op van het begrip 'contract' in deze context.

\section{Literatuur}

1. Berkestijn LGM van. Ontwikkelingen in de huisartsopleiding. Huisarts Wet 2003;46:672-5.

2. Bolhuis S. Leren en veranderen bij volwassenen. Bussum: Coutinho; 2001. p. 241-5.
3. Jong F de, Biemans H. Constructivistisch onderwijs. In: Vermunt J. Onderwijzen van kennis en vaardigheden. Onderwijskundig Lexicon III. Alphen aan den Rijn: Samson; 1998. p. 67-85.

4. Berkestijn LGM van. Leren leren. Over de vernieuwing van de huisartsopleiding. Huisarts Wet 2002;45:248-52.

5. Janssens S, Boes W, Wante D. Portfolio's: een instrument voor toetsing en begeleiding. In: Dochy $\mathrm{F}$, Mosselaar $\mathrm{H}$ van de. Assessment in onderwijs. Utrecht: Lemma; 2002. p. 203-20.

6. Elshout-Mohr M, Daalen-Kapteijns M van. Goed gebruik van portfolio's in competentiegerichte opleidingen. VELON Tijdschrift voor Lerarenopleiders 2003;24(4):5-13.

7. Grol R. Een structuurplan voor de meerjarige beroepsopleiding tot huisarts. Rapport ССВOH-01. Utrecht: Commissie CСBOH; 1985.

\section{De auteurs:}

Dr. Gerrit Locher is gedragswetenschappelijk medewerker. Mw. Binkey Koerten is ondersteunend medewerkster. Beide auteurs zijn werkzaam aan de Huisartsopleiding van het VUmc te Amsterdam.

\section{Correspondentieadres:}

Dr. Gerrit Locher, Huisartsopleiding VUmc, Overschiestraat 180, 1062 XK Amsterdam, tel: 020-4449346, fax: 020-4448379,g.locher@vumc.nl.

\section{Summary}

Introduction: In preparation for the implementation of the new curriculum for general practice vocational training, personal education programmes for GP trainees were introduced. We evaluated the formats of these programmes, how trainees used them, whether trainees thought working with the programmes was satisfactory, and how the programmes were used by GP trainers and staff of the training institute.

Methods: We investigated the above issues using a questionnaire that was administered to all GP trainees in the first and third year of their training.

Results: Out of a total of 72 trainees, 68 (90\%) returned completed questionnaires. The personal development programmes of most respondents were limited to learning issues. The majority used the programme in planning learning activities and in discussing their learning with GP trainers. A minority used it to give an account of their learning activities. The most useful aspects were dealing with gaps in learning and planning discussions with GP trainers. The intensity with which GP trainers used the programmes determined trainees' perceptions of their usefulness, although on the whole trainees were not very enthusiastic.

Conclusion and discussion: The results suggest that it may not be advisable to make personal education programmes the task and responsibility of individual trainees only. It seems preferable to view these programmes as contracts between trainees and trainers. The role of the training institute may be that of a coach who supports trainees and trainers in the compilation and use of personal education programmes. (Locher G, Koerten WH. The introduction of Personal Education Programmes in vocational training for general practice. Dutch Journal of Medical Education 2005;24(2):78-86.) 